\title{
Does contraceptive treatment in wildlife result in side effects? A review of quantitative and anecdotal evidence
}

\author{
Meeghan E Gray and Elissa Z Cameron ${ }^{1}$ \\ Department of Animal Biotechnology, Program in Ecology, Evolution and Conservation Biology, University of Nevada, \\ Reno, Nevada 89557, USA and ${ }^{1}$ Department of Zoology and Entomology, Mammal Research Institute, \\ University of Pretoria, 0002 Pretoria, South Africa
}

Correspondence should be addressed to M E Gray; Email: meeghang@unr.nevada.edu

\begin{abstract}
The efficacy of contraceptive treatments has been extensively tested, and several formulations are effective at reducing fertility in a range of species. However, these formulations should minimally impact the behavior of individuals and populations before a contraceptive is used for population manipulation, but these effects have received less attention. Potential side effects have been identified theoretically and we reviewed published studies that have investigated side effects on behavior and physiology of individuals or population-level effects, which provided mixed results. Physiological side effects were most prevalent. Most studies reported a lack of secondary effects, but were usually based on qualitative data or anecdotes. A meta-analysis on quantitative studies of side effects showed that secondary effects consistently occur across all categories and all contraceptive types. This contrasts with the qualitative studies, suggesting that anecdotal reports are insufficient to investigate secondary impacts of contraceptive treatment. We conclude that more research is needed to address fundamental questions about secondary effects of contraceptive treatment and experiments are fundamental to conclusions. In addition, researchers are missing a vital opportunity to use contraceptives as an experimental tool to test the influence of reproduction, sex and fertility on the behavior of wildlife species.
\end{abstract}

Reproduction (2010) 139 45-55

\section{Introduction}

Fertility control for population management of wildlife and zoo species has some advantages over other control methods, such as lethal control (Kirkpatrick 2007). For example, culling reduces population size, but also increases population growth rates, counteracting the goals of most population control operations (Garrott et al. 1991). Furthermore, there are ethical concerns about culling (Littin et al. 2004) such that public acceptance of lethal control is typically low when other management options are viable (e.g. Stout et al. 1997). However, for contraception to be successful for population control it must not only be safe, effective and long-acting, but also have minimal impact on the social organization, behavior, and ecology of populations with treated individuals (Castle \& Dean 1996). Contraceptive technologies are becoming increasingly effective, safe and long-lasting (Kirkpatrick \& Turner 2007), but despite several decades of contraceptive treatment, little research has considered secondary impacts, except in domestic animals. Fertility control is used to manage farm, domestic and recreational animals ( $\mathrm{D}^{\prime}$ Occhio 1993) and provides a viable and reversible alternative to de-sexing (e.g. cats, Ivanova et al. 1995, Gorman et al.
2002), but only if the animals behave similarly before and after treatment. In wildlife, the alternative is often lethal control which raises a plethora of other legal and logistical issues (e.g. Kirkpatrick 2007). Nonetheless, the side effects of contraception need to be understood for fertility control to be an effective management tool, even if alternative management practices have more extreme side effects (see Kirkpatrick 2007).

Contraceptive formulations either prevent ovulation, fertilization or implantation, or terminate pregnancy. Immunocontraception uses an animal's own immune system to prevent reproduction. The body produces antibodies in response to the injection of a foreign body, and the antibodies then interfere with critical events in reproduction. Several different types of immunocontraceptive formulations have been developed, including those against ova (Sacco 1987), sperm (Primakoff et al. 1988), and gonadotropins (Moudgal et al. 1986). The most commonly used formulation is porcine zona pellucida (PZP), which stimulates the production of antibodies to zona pellucida (ZP) when injected into the host (Aitken et al. 1984). These antibodies prevent sperm binding to the ZP sperm receptors, thereby preventing fertilization (Sacco et al. 1984). Infertility results, but females continue to cycle. Since the structure of these 
receptors is conserved, PZP inhibits fertility in a range of mammalian taxa (Wood et al. 1981, Mahi-Brown et al. 1985, Sacco 1987, Kirkpatrick et al. 1996). GNRH formulations, both agonists and active immunizations, result in a reduction of the release of $\mathrm{FSH}$ and $\mathrm{LH}$. Treated females thereby enter a variable length anestrous period (Talwar 1985). These GNRH formulations have been widely used in domesticated livestock as a practical application to improve carcass quality and to reduce aggressive behavior (i.e. Huxsoll et al. 1998, Kiyma et al. 2000). To a lesser extent they have been used for fertility control in both males and females of wildlife species (e.g. Miller et al. 2000a). Other common types of contraceptive agents include 1) melengestrol acetate (MGA), a progesterone-like drug that suppresses $\mathrm{LH}$, preventing ovulation, but allowing development of large follicles and endogenous estradiol, and 2) progesterone analogs that inhibit ovulation and/or prevent implantation, both of which have been used successfully in several zoo species (reviewed in Patton et al. (2007)). Surgical sterilization is also an option in some species, but presents some practical issues associated with surgery (i.e. catching, anesthesia, irreversibility, morbidity, and mortality) that make it unsuitable for most wildlife species.

The potential side effects of these contraceptive treatments have been considered theoretically, but few have been tested empirically. Nettles (1997) reviewed potential side effects, which included physiological effects, behavioral effects, population impacts and evolutionary impacts, and more recently suggested side effects include evolutionary effects (Magiafoglou et al. 2003, Cooper \& Larsen 2006) and impacts on disease transmission rates (Tuyttens \& MacDonald 1998, Caley \& Ramsey 2001, Miller et al. 2004). The diversity of contraceptive agents means that there is potential for a variety of secondary impacts. Here we review the literature to determine: 1) potential impacts on individuals and populations, 2) which impacts have been documented, and 3) which impacts have been empirically tested. Finally, we consider the implications of the side effects of contraception for addressing fundamental theoretical questions, particularly in behavioral ecology.

\section{Results}

\section{Trends in publications}

The reviewed studies emphasized pest animals and agriculturally important species. Several orders have been investigated, but studies concentrated on Artiodactyla (particularly deer and domestic cows), Perissodactyla (mainly horses), and Carnivora (particularly felids) (Supplementary Table 1, see section on supplementary data given at the end of this article). There was an overall increase in published papers from 1975 to 2002 (Fig. 1). These publication trends indicate

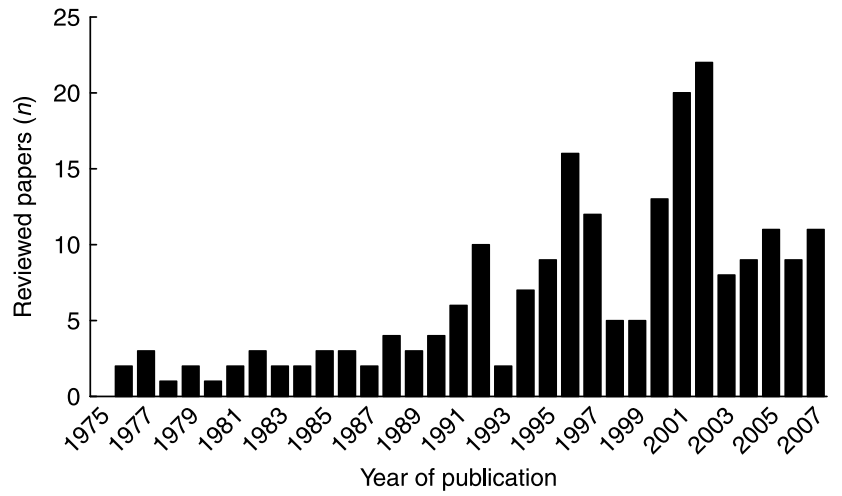

Figure 1 Publication trends of papers $(n=212)$ that investigated or reported on secondary effects of contraceptive agents from 1975 to 2007.

increasing interest in side effects with a peak in 2002 when a special issue of Reproduction Supplement (vol 60) was published. After this supplement, the rate of publication returned to a consistent pre-2001 level.

Most studies investigated the impacts of female contraceptives (Table 1), which is consistent with efficacy studies in wildlife which usually target females. Physiological responses were addressed in a high percentage of the papers (85\%) for both males and females. While physiological impacts are important, behavioral and population-level effects may be more relevant to the management of wild populations. Approximately $35 \%$ of the papers addressed individual behavior and $11 \%$ addressed population-level effects. Roughly $1 / 3$ of the papers $(30 \%)$ addressed more than one category. Only one paper investigated populationlevel effects in males, most likely because females are treated more often than males in wildlife populations (Table 1). Most of the research in the reviewed papers was done in captivity (84\%) and the majority of studies that investigated changes in behavior of contracepted individuals were conducted in captivity $(76 \%)$.

In this review, sample sizes, when reported, ranged from 1 to 353 for treated individuals and $0-230$ for control individuals, with an average sample size of $31.7 \pm 49.0$ (median 17) treated individuals and $18.2 \pm 30.0$ (median 9) for controls, indicating high variability among studies. Most studies were of relatively

Table 1 A comparison of the 212 reviewed papers (\%) based on sex and category that were included in the review. Total papers refers to the combined set of papers only based on sex, while the rest of the categories are specific to each sex.

\begin{tabular}{lcccc}
\hline & Total papers & Behavior & Physiology & Population \\
\hline $\begin{array}{c}\text { Female } \\
(n=145)\end{array}$ & 68 & 30 & 83 & 14 \\
$\begin{array}{c}\text { Male } \\
(n=50)\end{array}$ & 24 & 46 & 90 & 2 \\
$\begin{array}{c}\text { Both } \\
(n=17)\end{array}$ & 8 & 41 & 88 & 12 \\
\hline
\end{tabular}


short duration, with an average duration of $1.8 \pm 2.4$ years; although data collection was often conducted in short field periods of a few days or weeks over the course of the entire study, probably resulting in an overestimate of average study length.

\section{Documented secondary effects}

Several secondary effects are theoretically possible, and these are summarized in Table 2. Only a few hypothesized impacts have not been investigated, with most being studied at least once. However, few studies produced consistent results, even among studies using the same formulations. The main impacts are summarized below.

\section{Physiology}

\section{How does contraception impact internal organs?}

The impact of contraception on internal organs has received the most attention, with a total of 134 studies published. Changes in ovarian structure and function were found in most studies ( $82 \%$, Table 2$)$, which is not surprising since contraceptive formulations act directly on reproductive functioning, and so changes in reproductive organ histology and function are more likely than other impacts. Most changes that occurred to the reproductive tract were changes to follicle number, weight and size with the use of GNRH formulations (McNeilly \& Fraser 1987, D'Occhio \& Kinder 1995, Gong et al. 1995, Maclellan et al. 1997) and PZP

Table 2 Theoretical side effects of contraceptives and the number of studies that investigated these side effects. Both experimental and anecdotal papers are included in this table.

\begin{tabular}{|c|c|c|c|}
\hline Side-effect & Theoretical & ${ }^{*}$ Effect $(n)$ & No effect $(n)$ \\
\hline \multicolumn{4}{|l|}{ Physiological } \\
\hline Harmful effects on pregnant animals & Nettles (1997) & & \\
\hline Stillbirth & & 8 & 1 \\
\hline Abnormal offspring & & 2 & 1 \\
\hline Inhibition of parturition or dystocia & Nettles (1997) & 2 & 0 \\
\hline Changes in ovarian structure or function & Nettles (1997) & & \\
\hline Associated with contraceptive mechanism & & 17 & 11 \\
\hline Associated with pathological changes & & 34 & \\
\hline Changes in lactation or mammary glands & Nettles (1997) & 1 & 4 \\
\hline Changes in secondary sex characteristics & Seal (1991) and Nettles (1997) & 0 & 0 \\
\hline Changes in bodyweight or condition & Nettles (1997) & & \\
\hline Increased in treated females & & 9 & 26 \\
\hline Decreased in males & & 1 & 0 \\
\hline Toxicity & Nettles (1997) & 0 & 0 \\
\hline Interference with diagnostic tests & Nettles (1997) & 1 & 0 \\
\hline Abscesses or inflammatory reactions & Nettles (1997) & 14 & 8 \\
\hline \multicolumn{4}{|l|}{ Individual behavior } \\
\hline Changes in behavior & Nettles (1997) & & \\
\hline Sexual activity & & 9 & 5 \\
\hline Increased movement & & 2 & 1 \\
\hline Activity patterns & & 2 & 8 \\
\hline Increased irritability or aggression & & 3 & 0 \\
\hline Social disruption, change in status, territory loss & & 5 & 5 \\
\hline \multicolumn{4}{|l|}{ Population-level } \\
\hline Changes in sex ratio & Nettles (1997) & & \\
\hline Due to immigration & & 1 & 0 \\
\hline Offspring sex ratios & & 0 & 0 \\
\hline Changes in annual breeding season & Nettles (1997) & 7 & 2 \\
\hline Ecological alterations & Nettles (1997) & & \\
\hline Home range or territory size & & 3 & 4 \\
\hline Increased immigration or emigration & & 0 & 1 \\
\hline Change in habitat use & & 1 & 1 \\
\hline Increased longevity or survival & & 6 & 2 \\
\hline Increased survival of offspring & & 3 & 2 \\
\hline Impact on fertility of young & Nettles (1997) & 0 & 1 \\
\hline Improved breeding of non-treated females & & 1 & 0 \\
\hline Disease transmission rates & $\begin{array}{l}\text { Tuyttens \& } \\
\text { MacDonald (1998), Caley \& Ramsey } \\
\text { (2001) and Miller et al. (2004) }\end{array}$ & 1 & 2 \\
\hline \multicolumn{4}{|l|}{ Evolutionary level } \\
\hline Genetic resistance & Magiafoglou et al. (2003) & 0 & 0 \\
\hline $\begin{array}{l}\text { Genetic changes influencing disease resistance } \\
\text { or immune function }\end{array}$ & $\begin{array}{l}\text { Nettles (1997) and Cooper \& Larsen } \\
(2006)\end{array}$ & 0 & 0 \\
\hline
\end{tabular}

\footnotetext{
"References are in Supplementary Table 2, see section on supplementary data given at the end of this article.
} 
treatment (Dunbar et al. 1989, Kirkpatrick et al. 1992, Kitchener et al. 2002, Curtis et al. 2007). However, more serious side effects have been reported including increased inflammation of the uterus by intrauterine devices (Daels \& Hughes 1995) and alterations to ovarian function, oophoritis and cyst formation with PZP treatment (Mahi-Brown et al. 1988, Sehgal et al. 1989, Rhim et al. 1992, Stoops et al. 2006, Curtis et al. 2007). In addition, MGA implants can increase mineralization and cystic hyperplasia in felids (Munson et al. 2002) and cause endometrial hyperplasia (Sokolowski \& VanRavenswaay 1976). Consequently, changes to the ovaries or female reproductive tract were consistently found for all contraceptive treatments.

In domesticated livestock, GNRH immunization has been used to improve carcass characteristics by increasing lean meat (Huxsoll et al. 1998), feeding efficiency (Cook et al. 2001) and live weight (Bonneau et al. 1994, Zeng et al. 2002), and treatment usually resulted in positive effects on carcass traits, or no effect. Milk production did not seem to be influenced by contraception in the few studies in which it has been investigated (GNRH agonist: Mattos et al. 2001; progesterone: Nave et al. 2000), although there was some evidence of mammary hyperplasia in cats treated with progesterone (progestin: Loretti et al. 2005).

In addition to effects on internal organs, several studies (64\%, Table 2) found inflammation or abscesses at the injection site. The majority of these papers examined inflammations due to injectable contraceptive formulations $(n=18)$ and most found some inflammation at the injection site $(67 \%)$. Most of these papers $(n=14)$ investigated the impacts of PZP treatment and the majority found injection site reactions (71\%). However, the injection site reactions were often associated with the type of adjuvant (e.g. Freund's Complete Adjuvant) used in association with contraceptive treatment, and these effects have been reduced with the use of modified adjuvants (Deigert et al. 2003). These injection site reactions usually healed quickly with no long-term health effects. Overall, most of the treatments showed little to no impacts on internal organs other than the ovaries (or testes) and some of the effects were considered positive.

\section{Does contraception alter body condition?}

Without the costs of lactation and gestation, females should hypothetically have improved condition and health, possibly leading to increased longevity and lifespan (Williams 1966). These impacts could extend beyond treated females. For example, untreated males may lose condition in the presence of contracepted females due to prolonged breeding activities ( $\mathrm{Ji}$ et al. 2000). Some studies have confirmed that treated females are in better condition than untreated conspecifics (26\% of reviewed studies), but the majority found no difference, or that differences did not last (Table 2). For example, PZP treatment increased female condition in both feral horses and white-tailed deer in some studies (McShea et al. 1997, Turner \& Kirkpatrick 2002), but not in others (Walter et al. 2003). Generally, females treated with GNRH show no changes in weight or condition (Miller et al. 1997, D'Occhio et al. 2002, Herbert et al. 2005, 2006, Rubion et al. 2006). Finally, both longevity and offspring survival could theoretically be influenced by contraceptive treatment because untreated females may have more successful reproduction due to reduced competition for resources. The impacts of these factors on population dynamics can counteract the desired impact of the contraceptive treatment in reducing population size (see Williams et al. 2007) and such population-level effects are discussed later.

\section{Are some contraceptive agents reversible?}

For contraceptive treatment to be an effective management tool, it usually needs to be reversible (Kirkpatrick \& Turner 1991). A long term study of feral horses showed that PZP was reversible even when females were treated for several years (Kirkpatrick \& Turner 2002). However some females appeared not to return to full fertility after long-term PZP treatment and similar side effects were seen with GNRH treatments in deer (e.g. Miller et al. 2000a). Consequently, most wildlife contraceptives are reversible, or have minimal impact after prolonged use.

\section{Individual behavior}

Do activity patterns change in treated individuals?

Most studies suggest that activity patterns were unchanged after contraceptive treatment $(80 \%$, Table 2). With PZP treatment, no changes were detected in activity budgets of elk, horses, elephants, and whitetailed deer females (McShea et al. 1997, Heilmann et al. 1998, Powell 1999, Delsink et al. 2002), although the increased number of estrous cycles resulted in PZP treated white-tailed does being more active than control females (McShea et al. 1997). GNRH did not change activity budgets in treated kangaroo females (Woodward et al. 2006), nor did progesterone implants in kangaroos (Poiani et al. 2002), or fruit bats (Hayes et al. 1996). However, MGA treatment caused baboons to decrease their time foraging (Portugal \& Asa 1995). Overall, few studies reported changes in activity patterns after contraceptive treatment.

\section{Does rank and dominance change in treated females?}

Rank and dominance are important in social mammals (Ellis 1995). By changing the levels of hormones or cycling patterns, females could become more or less 
aggressive, which could have implications for behavior, social structure and welfare. Such side effects have been used by captive managers (e.g. GNRH to control aggressive behavior, Patton et al. 2001), but the few studies on wildlife have produced mixed results $(50 \%$ showed changes Table 2). In captive felids, females treated with PZP had increased levels of irritability, masculine behavior, and aggression (Harrenstien et al. 2004), and in white-tailed deer, treated females associated less frequently with conspecifics (Bertrand et al. 1996). MGA treatment in tamarins caused a decrease in affiliative and sexual interactions, with a subsequent increase in aggression towards other females (De Vleeschouwer et al. 2000, 2003). Poiani et al. (2002) found that progesterone treatment altered the amount of time males spent with females, as males preferred to be in groups with untreated females. In elephants, the matriarch remained in place after treatment with PZP (Delsink et al. 2002), but changes occurred with hormonal treatments (unpublished study described in Fayrer-Hosken et al. (2000)). PZP treatment did not change the spatial relationship between females and males in horse harem bands (Powell 1999), although all females had been treated with PZP at some point, confounding the conclusions. Finally, surgical sterilization had little impact on coyote pair bond maintenance or territorial behavior (Bromley \& Gese 2001), and no changes in social hierarchy were observed in brushtail possums with GNRH treatment ( Jolly et al. 1996).

Unfortunately, many of the studies reporting no change in social structure have either used opportunistic observations of social groups, rather than quantitative techniques, or have been of short duration. Consequently, the results are inconclusive, and studies that specifically and intensively investigate behavioral changes at a fine level over a long time period are urgently needed.

\section{Are home ranges and movement patterns altered?}

If sexual behavior is altered in treated females, movement patterns could also change. PZP treatment resulted in no difference in space use or home range size in elephants and white-tailed deer (Delsink et al. 2002, Hernandez et al. 2006), similar to surgically sterilized foxes (Saunders et al. 2002). In contrast, surgically sterilized female rats had larger ranges than both control and hormonally sterilized females (Jacob \& Matulessy 2004). In addition, hormonally sterilized female rats abandoned burrows more often, suggesting a change in dominance or social status, although overall habitat use was not changed (Jacob \& Matulessy 2004). Male home range size may also be impacted, as found in brushtail possums (Ramsey 2007). Sterilization resulted in no difference in territory size, overlap or territorial behavior between controls and treated coyote packs (Bromley \& Gese 2001). Consequently, most studies suggest that contraception had minimal impact on home range size and movement patterns, but there was some evidence that male kangaroos alter their movement patterns to be in groups of untreated females, or with treated females during the nonbreeding season (Poiani et al. 2002).

\section{Do sexual interactions and breeding behavior change?}

Changing the fertility of individual females could impact sexual interactions, especially in PZP-treated individuals because the number of estrous cycles is increased (i.e. McShea et al. 1997, Heilmann et al. 1998, Miller et al. 2000b, 2000c, Curtis et al. 2002). There was some evidence that breeding behavior changed in treated females (Table 2), and this varied with contraceptive type. Does treated with GNRH agonists had fewer estrus events (Miller et al. 2000a), but female wapiti showed no difference in copulatory behaviors (Baker et al. 2004). Treatment with progesterone analogs showed similar results to GNRH, but more males were seen in groups of control females (Poiani et al. 2002). Ji et al. (2000) suggested that males were attracted to areas with sterilized females, potentially increasing male mortality. In contrast, with PZP treatment, females remained sexually active after the end of the breeding season and showed an increase in estrus events (McShea et al. 1997, Heilmann et al. 1998, Miller et al. 2000b, 2000c). Although changes in breeding behavior appeared to be related to contraceptive formulations, $64 \%$ of the studies found changes in estrus and breeding behavior (Table 2), suggesting that these changes should be expected.

\section{Does contraception impact the overall welfare of individuals?}

Animal welfare refers to the systematic concern for the well-being of animals. The assessment of welfare involves the examination of both emotional and physical states (Fraser 1995). The reviewed impacts on physiology and behavior suggest that contraception had little impact on overall welfare of individuals, particularly compared to the alternative options (see Kirkpatrick (2007)). While most studies found some changes in physiology or behavior, these changes may not impact the individual enough to affect their well-being, as most studies found no changes to activity, movements or rank of treated females. However, these conclusions are based largely on qualitative and anecdotal studies and there were no studies that specifically set out to address welfare of individuals. While welfare can be difficult to measure, there are many ways to objectively evaluate welfare (Dawkins 2001, Scott et al. 2003). For example, measuring stress levels in both treated and control individuals could give an assessment of overall wellbeing, yet none of the reviewed studies took a systematic approach to address this issue. In addition, some studies 
indicated that changes could occur to non-treated animals in the population (e.g. males), which needs to be considered in future research. Furthermore, since most of these studies were conducted in captivity, the applicability to free-ranging populations may be limited since conditions in captivity do not necessarily mimic natural conditions. Given all of these issues, the assessment of welfare implications of contraceptive treatment is a research priority.

\section{Population-level effects}

Do survival, abundance, and age class distribution change in treated populations?

Contraception reduces the costs of reproduction, and could therefore result in increased body condition and longer lifespan, thereby altering population dynamics. Furthermore, the offspring of untreated females may have less competition for resources, enhancing their survival and working against the goals of the management operation. Few studies had the longitudinal data required to investigate increased survival, but $75 \%$ found an increase in longevity or survival in individuals. For example, PZP treated feral horse mares lived longer, resulting in a new age class ( $>25$ years) not present before treatment (Turner \& Kirkpatrick 2002). Therefore, while contraception may limit offspring production, these benefits may be offset by decreased mortality in older individuals, negating the population level effects of contraceptive treatment. In addition, both adults and juveniles had increased survival in surgically sterilized rabbits (Williams et al. 2007), which meant that the majority of females must be sterilized to reduce population size (Williams et al. 2007). Furthermore, non-treated females showed improved breeding success (Chambers et al. 1999), which also counteracted the reduction of population growth rates by contraception. Finally, while the sex ratio of offspring could change due to increased maternal condition (e.g. Cameron 2004), this has yet to be investigated, although Ji et al. (2000) recorded a change in population sex ratios in brushtail possums, probably as a result of male dispersal. Overall, contraceptive treatment appears to increase longevity in treated females and, in some cases, non-treated individuals.

\section{Does contraception decrease disease transmission?}

If contraception decreases sexual interactions, there may be a decrease in overall social interactions which could decrease the level of disease transmission. Diseases could also be decreased in a treated population simply from lower densities of animals and healthier conditions (see body condition section). This decrease would be advantageous in certain pest species, such as the brushtail possum, which have a high population size, and are carriers of economically or ecologically important diseases, such as bovine tuberculosis (Caley \& Ramsey 2001, Ramsey 2007). In addition, a potential decrease of brucellosis transmission is predicted in bison with GNRH treatment (Miller et al. 2004), as anestrous females would be unable to spread the disease due to lack of offspring production. Both of these circumstances would result in a positive side effect of contraceptive treatment. Alternatively, if sexual interactions increase, such as in the case of PZP treatment, there could be a potential increase in the transmission of certain diseases. While there has been little research that addresses these effects, most studies concur that disease transmission rates remain unchanged with contraceptive treatment (Kerr et al. 1998, Williams et al. 2007). However, the potential to reduce disease transmission exists (Ramsey 2007) and studies on rabbits showed a decrease in flea abundance (Twigg et al. 2000, Williams et al. 2007); possibly indicating a decrease in overall interactions between individuals. More research is clearly required.

\section{Is the mating season extended?}

Mating behavior can demand high levels of energy for both sexes. In species with a discrete breeding season, the lengthening of the season could impact the survival and welfare of treated females and nontreated males. Most studies showed a change in the annual breeding season where it was investigated $(78 \%$, Table 2$)$. Treatment with PZP increased breeding behavior, caused later fawning dates, and increased sexual activity outside the normal breeding season in several studies (McShea et al. 1997, Heilmann et al. 1998, Miller et al. 2000b). However, no differences were reported in populations with females treated with GNRH (Miller et al. 2000a, Baker et al. 2002, 2004, Woodward et al. 2006, Conner et al. 2007), or progesterone (Poiani et al. 2002). Differences in the actions of these formulations and their contrasting effects on cycling probably account for the differences in the impacts on the breeding season. Consequently, the type of contraceptive treatment should be considered for species with a discrete breeding and birthing season. These side effects could have animal welfare implications as these changes could lead to a reduction in the survival of treated females, untreated males and offspring.

\section{Meta-analysis}

Of the 212 reviewed papers, 54 (25\%) experimentally tested the secondary effects of contraception and reported their results in sufficient detail to be included in the meta-analysis. Studies were classified as experimental if the authors described an experiment with controls, and used statistical analysis of their results. We did not attempt to judge the robustness of their experimental design since we could not always judge 


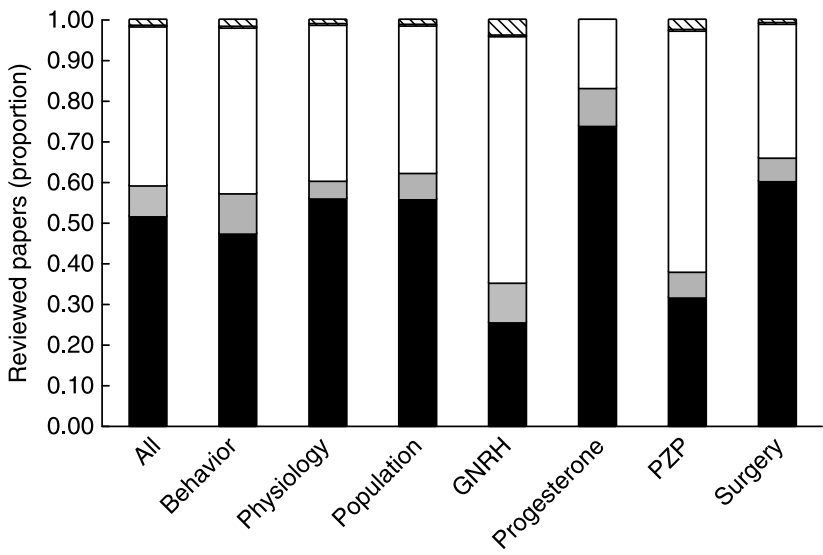

Figure 2 Wildlife studies that empirically tested $(n=54)$ if contraceptive treatment produced side effects that either showed significant support ( $\square$ ) or non-significant trend to support ( $\square$ ), or no significant variation $(\square)$, or significant support in the opposite direction to that predicted ( $\nabla)$.

from methodological descriptions whether these represented true experiments with randomized subjects and appropriate controls. Although the quality of experiments may vary, they provide results suitable for metaanalysis, and enable the detection of general trends. From our qualitative review, most papers concluded no significant secondary effects were found. However, the quantitative studies produced contrasting results. From the 339 test statistics from the 54 papers, $52 \%$ found side effects from contraception and an additional $8 \%$ showed a non-significant trend suggesting side effects. The support varied between contraceptive types and between secondary effect types, with progesterone treatments and physiological studies reporting the most side effects (Fig. 2). Despite this variation, all metaanalyses yielded highly significant $z$ values for the difference between treated and control groups and confirmed that side effects consistently occurred where investigated regardless of study category or treatment type (Table 3). The magnitude of the overall effect size was medium, as $r$ ranged from 0.17 to 0.39 . Furthermore, there was no significant heterogeneity of effect sizes within analyses, suggesting that studies were measuring the same thing and coming to the conclusion that side effects occur when investigated. Therefore, contraceptive treatment resulted in changes to the physiology and behavior of individuals, and impacted populations with treated individuals.

An interesting contrast thereby arises in which quantitative studies showed that side effects were consistently found, whereas qualitative studies and anecdotal reports suggest that side effects were generally absent. While a publication bias is possible, most studies were predominantly publishing results on efficacy, such that data on side effects would not influence publication potential. Consequently, more studies specifically investigating secondary effects are required to quantify the impacts of contraceptive treatment on physiology, behavior and population dynamics.

\section{Discussion}

\section{Future directions}

While there have been an increasing number of studies on side effects, much is still unknown. Unfortunately, many of the reviewed studies were not designed to investigate the side effects and many conclusions were based on small sample sizes, anecdotal reports, or lacked true controls. Conclusions based on data from studies designed to investigate efficacy may not be methodologically suitable for testing for behavioral or ecological effects. Many studies were designed to test efficacy, and the side effects reported were based only on short-term observations. Many studies on efficacy concluded 'no change' for side effects based on anecdotal observations, but these studies did not directly investigate the physiology, behavior or ecology during the study, limiting the conclusions. This contrasts with the meta-analysis further questioning the validity of qualitative studies reporting 'no change'. While the meta-analysis does not account for the severity of the effect, all of the major contraceptive treatments resulted in side effects (Table 3). Thus, these qualitative studies represent an interesting foundation, but future research

Table 3 Meta-analysis of reviewed papers on wildlife species when contraceptive treatment was investigated for secondary effects ( $n=54$ ). All data are generated from Meta 5.3 including effect size (difference between treated and control groups among all studies), $Z_{\text {weighted }}$ (the significance of the effect size), heterogeneity (difference of measurements among studies) and the $P$ value of the heterogeneity.

\begin{tabular}{|c|c|c|c|c|c|c|c|}
\hline Measure & $n_{\text {studies }}$ & $n_{\text {statistics }}$ & $n_{\text {datapoints }}$ & Effect size $(r)$ & $Z_{\text {weighted }}$ & Heterogeneity $\left(x^{2}\right)$ & $P$ value \\
\hline All studies & 54 & 339 & 9471 & 0.1993 & $19.4002^{\mathrm{a}}$ & 338.1099 & 0.4881 \\
\hline Physiology & 29 & 91 & 2679 & 0.2126 & $11.1917^{\mathrm{a}}$ & 102.8470 & 0.1673 \\
\hline Behavior & 27 & 171 & 3872 & 0.2380 & $14.8088^{\mathrm{a}}$ & 156.9311 & 0.7553 \\
\hline Population & 15 & 77 & 2920 & 0.3041 & $8.9712^{a}$ & 75.6087 & 0.4911 \\
\hline PZP & 16 & 79 & 3842 & 0.1748 & $10.8354^{\mathrm{a}}$ & 76.9119 & 0.5136 \\
\hline GNRH & 8 & 51 & 1149 & 0.2421 & $8.2056^{\mathrm{a}}$ & 35.5526 & 0.9388 \\
\hline Progesterone & 16 & 96 & 2655 & 0.1809 & $9.3193^{a}$ & 81.8345 & 0.8300 \\
\hline Surgery & 13 & 121 & 2055 & 0.3884 & $17.6090^{\mathrm{a}}$ & 126.4755 & 0.3251 \\
\hline
\end{tabular}

\footnotetext{
${ }^{\mathrm{a} A l l} z$ values were significant; $P<0.0001$.
} 
requires more detailed behavioral and ecological protocols, larger sample sizes, and longer study durations.

\section{Evolutionary level}

No evolutionary level questions have been investigated, but are most relevant for future impacts (Table 2). Two main impacts of immunocontraception have been proposed; 1 ) genetic resistance could evolve, similar to the response seen to other biological control agents (Magiafoglou et al. 2003), and 2) immunocontraceptives could be selecting for immuno-compromised individuals since those treated females that do breed have a lower immune response to the contraceptive (Nettles 1997, Cooper \& Herbert 2001). These aspects require long-term research which has not been possible to date. Nonetheless, given the potential implications of either of these changes, research is urgently required in this field.

\section{Conclusions}

While physiological effects have been well-documented, there is less consistency in studies investigating behavioral or ecological side effects, compounded by the tendency for studies to be designed to investigate efficacy specifically and side effects only opportunistically. Such studies often lack appropriate controls, sampling methodology or time scales. Those studies that have specifically investigated side effects consistently find them. While contraception is currently supported as a humane treatment by many managers, researchers and advocacy groups, research in this field has not extended much beyond the scope of management concerns.

Both physiological and behavioral effects can impact population dynamics. The goal of contraceptive treatment is to manipulate population dynamics, and consequently it is imperative to understand populationlevel effects, some of which compromise the effectiveness of contraceptive treatment (such as through increased breeding in untreated females or increased survival of offspring), while others could enhance effectiveness (such as a male biased sex ratio). To be an effective tool, we need to understand these impacts. Furthermore, most research examined short term effects and research is needed that addresses questions beyond one estrous cycle or breeding season. For example, no study investigated how genetic diversity or immunity could change over time. In addition, most studies, including behavioral studies, were done in captivity, which often limits the application to wildlife species, further suggesting the need for long term experimental studies on wildlife populations.

Finally, contraception provides a powerful tool to address fundamental questions in biology but such applications have not been realized to date.
By manipulating fertility we can address questions regarding, for example, the costs of reproduction, importance of copulation in maintaining social structure and parental investment strategies. This would enable us to simultaneously address management questions, questions about contraceptive actions and secondary effects, and questions in basic biology, thereby maximizing the utility of contraception research.

\section{Materials and Methods}

We searched ISI Web of Science (1975-2007) for 'immunocontraception' and 'contraception'. Additional searches were made to narrow the papers to those with the terms 'side effects' and 'secondary effects', and we further searched the literature from the cited section of each paper to find more studies that were not identified in the initial search. Only papers that included applications to mammalian wildlife, zoo, or livestock species were used in the review, and humans were excluded. Papers that only researched efficacy or impacts of contraception on fertility directly were not included.

Initially we reviewed the theoretically suggested side effects. We then compiled all the studies that had addressed secondary effects either directly or during the course of a study on efficacy. We defined a side effect as an unintended or unwanted secondary effect and use the terms side effect and secondary effect interchangeably. Both of these terms refer to unintended side effects, but could be positive, neutral or negative. We considered changes to ovarian structure as side effects as both changes induced by pathology or association with the mechanism of contraceptive action. Pathological changes would include cyst formation, hyperplasia, abnormal tissue formation, as well as changes that occurred from a contraceptive treatment where the intended purpose was not associated with ovarian function (e.g. block fertilization). This resulted in the classification of most papers that researched GNRH formulations as changes associated with the mechanism of contraceptive action since GNRH formulations directly act on hormones that regulate cycling and oocyte development. This definition also resulted in papers that investigated PZP being classified under pathological changes. In some of these cases the side effects are absolutely expected, but nonetheless they are secondary to the main contraceptive action and therefore considered side effects.

A total of 212 papers were found that investigated secondary effects or reported side effects noticed during research on efficacy (the full list is presented as Supplementary Appendix 1, see section on supplementary data given at end of this article). The papers fell into three categories; 1 ) physiological effects, 2) behavioral effects on the individuals, and 3) population-level effects, which we use hereafter. From those papers, we considered sex, species, sample sizes, length of study, type of effect investigated and if that effect had an impact on the animals. We then compared the theoretical effects with the empirical evidence to determine which effects seemed to be supported, or not supported, and in which areas more research is required. 


\section{Meta-analysis}

From the reviewed papers, we analyzed studies that empirically tested if side effects were found in treated wildlife populations through a meta-analysis in order to estimate the magnitude of the experimental effect (effect size). We only included wildlife populations and excluded wildlife in zoos if the contraceptive treatment was used intentionally to change behavior (i.e. decreasing aggression or sexual activity), so as not to skew the analysis towards side effects. In addition, in an effort to be conservative, livestock papers were excluded since $87 \%$ of these studies reported side effects and most of these papers used the contraception to make a change. Every meta-analysis suffers from the possibility of publication bias; therefore every attempt was made to remove publishing bias by the previously described methods. In addition, our search results included papers that primarily investigated efficacy but reported on side effects in order to reduce this bias.

For the meta-analysis we used the $P$ values and sample size reported in each study in order to obtain a combined effect size $(r)$. Effect sizes were weighted for sample size and indicate the strength of association across the selected studies. The corresponding $Z_{\text {weighted }}$ value provides the significance of the difference between treated (contracepted) and control groups. In addition, we calculated a $\chi^{2}$ statistic to test for heterogeneity of results across the selected studies. A random effect model was used in order to account for differences in both effect size and sampling error (Gurevitch \& Hedges 1999). A total of 54 papers were included that empirically tested secondary effects from contraceptive treatment. From those papers, all measures were treated as separate statistics. If there was not sufficient evidence to determine $P$ values and sample sizes, the papers (or statistics) were excluded from the analysis. An overall analysis was done, in which all experimental studies were included, regardless of treatment type and study classification. We then conducted separate analyses to test for differences within each side effect category (physiology, behavior and population-level effects) and contraceptive type (GNRH, progesterone, $\mathrm{PZP}$, and surgery). The meta-analysis was conducted using META, v 5.3 (Schwarzer 1989).

\section{Supplementary data}

This is linked to the online version of the paper at http://dx.doi. org/10.1530/REP-08-0456.

\section{Declaration of interest}

The authors declare that there is no conflict of interest that could be perceived as prejudicing the impartiality of the research reported.

\section{Funding}

This work was supported by the Nevada Arid Rangeland Initiative (grant numbers NOA15353CG, 110615253BS, 140115253BS, 140215253BS) and Hatch Grant (grant number $13215353 \mathrm{BS})$.

\section{Acknowledgements}

We thank D Thain, S Jenkins, M Ashley, EECB Peer Discussion Group and two anonymous reviewers for valuable comments on the manuscript.

\section{References}

Aitken R, Richardson DW \& Hulme M 1984 Immunological interference with the properties of the zona pellucida. In Immunological Aspects of Reproduction in Mammals, pp 305-325. Ed. DB Crighton. London: Butterworths.

Baker DL, Wild MA, Conner MM, Ravivarapu HB, Dunn RL \& Nett TM 2002 Effects of $\mathrm{GnRH}$ agonist leuprolide on reproduction and behavior in female wapiti Cervus elaphus nelsoni. Reproduction Supplement 60 155-167.

Baker DL, Wild MA, Conner MM, Ravivarapu HB, Dunn RL \& Nett TM 2004 Gonadotropin-releasing hormone agonist: a new approach to reversible contraception in female deer. Journal of Wildlife Diseases $\mathbf{4 0}$ 713-724.

Bertrand MR, DeNicola AJ, Beissinger SR \& Swihart RK 1996 Effects of parturition on home ranges and social affiliations of female white-tailed deer. Journal of Wildlife Management 60 899-909.

Bonneau M, Dufour R, Chouvet C, Roulet C, Meadus W \& Squires EJ 1994 The effects of immunization against luteinizing-hormone-releasing hormone of performance, sexual development, and levels of boar taintrelated compounds in intact male pigs. Journal of Animal Science $\mathbf{7 2}$ $14-20$.

Bromley C \& Gese EM 2001 Effects of sterilization on territory fidelity and maintenance, pair bonds, and survival rates of free-ranging coyotes. Canadian Journal of Zoology 79 386-392.

Caley P \& Ramsey D 2001 Estimating disease transmission in wildlife, with emphasis on leptospirosis and bovine tuberculosis in possums, and effects of fertility control. Journal of Applied Ecology 38 1362-1370.

Cameron EZ 2004 Facultative adjustment of mammalian sex ratios in support of the Trivers-Willard hypothesis: evidence for a mechanism. Proceedings of the Royal Society of London, Series B: Biological Sciences 271 1723-1728.

Castle PE \& Dean J 1996 Molecular genetics of the zona pellucida implications for immunocontraceptive strategies. Journal of Reproduction and Fertility Supplement $\mathbf{5 0}$ 1-8.

Chambers LK, Singleton GR \& Hinds LA 1999 Fertility control of wild mouse populations: the effects of hormonal competence and an imposed level of sterility. Wildlife Research 26 579-591.

Conner MM, Baker DL, Wild MA, Powers JG, Hussain MD, Dunn RL \& Nett TM 2007 Fertility control in free-ranging elk using gonadotropinreleasing hormone agonist leuprolide: effects on reproduction, behavior, and body condition. Journal of Wildlife Management 71 2346-2356.

Cook RB, Popp JD, McAllister TA, Kastelic JP \& Harland R 2001 Effects of immunization against $\mathrm{GnRH}$, melengestrol acetate, and a trenbolene acetate/estradiol implant on growth and carcass characteristics of beef heifers. Theriogenology 55 973-981.

Cooper DW \& Herbert CA 2001 Genetics, biotechnology and population management of over-abundant mammalian wildlife in Australasia. Reproduction, Fertility, and Development 13 451-458.

Cooper DW \& Larsen E 2006 Immunocontraception of mammalian wildlife: ecological and immunogenetic issues. Reproduction 132 821-828.

Curtis PD, Pooler RL, Richmond ME, Miller LA, Mattfeld GF \& Quimby FW 2002 Comparative effects of GnRH and porcine zona pellucida PZP immunocontraceptive vaccines for controlling reproduction in whitetailed deer Odocoileus virginianus. Reproduction Supplement $\mathbf{6 0}$ 131-141.

Curtis PD, Richmond ME, Miller LA \& Quimby FW 2007 Pathophysiology of white-tailed deer vaccinated with porcine zona pellucida immunocontraceptive. Vaccine 25 4623-4630.

Daels PF \& Hughes JP 1995 Fertility control using intrauterine devices: an alternative for population control in wild horses. Theriogenology $\mathbf{4 4}$ 629-639. 
Dawkins MS 2001 How can we recognize and assess good welfare? In Coping with Challenge: Welfare in Animals Including Humans, pp 63-76. Ed. DM Broom. New York: Dahlem University Press.

Deigert FA, Duncan AE, Frank KM, Lyda RO \& Kirkpatrick JF 2003 Immunocontraception of captive exotic species III contraception and population management of fallow deer (Cervus dama). Zoo Biology 22 261-268.

Delsink AK, van Altena JJ, Kirkpatrick J, Grobler D \& Fayrer-Hosken RA 2002 Field applications of immunocontraception in African elephants Loxodonta Africana. Reproduction Supplement 60 117-124.

De Vleeschouwer K, Van Elsacker L, Heistermannm M \& Leus K 2000 An evaluation of the suitability of contraceptive methods in golden-headed lion tamarins Leontopithecus chrysomelas, with emphasis on melengestrol acetate MGA implants: (II) endocrinological and behavioral effects. Animal Welfare 9 385-401.

De Vleeschouwer K, Leus K \& Van Elsacker L 2003 Stability of breeding and non-breeding groups of golden-headed lion tamarins (Leontopithecus chrysomelas). Animal Welfare 12 251-268.

D'Occhio MJ 1993 Immunological suppression of reproductive functions in male and female mammals. Animal Reproduction Science 33 345-372.

D'Occhio MJ \& Kinder JE 1995 Failure of the LH-releasing hormone agonist, deslorelin, to prevent development of a persistent follicle in heifers synchronized with norgestomet. Theriogenology 44 849-857.

D'Occhio MJ, Fordyce G, Whyte TR, Jubb TF, Fitzpatrick LA, Cooper NJ, Aspden WJ, Bolam MJ \& Trigg TE 2002 Use of GnRH agonist implants for long-term suppression of fertility in extensively managed heifers and cows. Animal Reproduction Science 74 151-162.

Dunbar BS, Lo C, Powell J \& Stevens JC 1989 Use of a synthetic peptide adjuvant for the immunization of baboons with denatured and deglycosolated pig zona pellucida proteins. Fertility and Sterility $\mathbf{5 2}$ 311-318.

Ellis L 1995 Dominance and reproductive success among nonhuman animals: a cross-species comparison. Ethology and Sociobiology $\mathbf{1 6}$ 257-311.

Fayrer-Hosken RA, Grobler D, van Altena J, Bertschinger HJ \& Kirkpatrick JF 2000 Immunocontraception of African elephants. Nature 407149.

Fraser D 1995 Science, values and animal welfare: exploring the 'inextricable connection'. Animal Welfare 4 103-117.

Garrott RA, Siniff DB \& Eberhardt LL 1991 Growth rates of feral horse populations. Journal of Wildlife Management 55 641-648.

Gong JG, Bramley TA, Gutierrez CG, Peters AR \& Webb R 1995 Effects of chronic treatment with a gonadotrophin-releasing hormone agonist on peripheral concentrations of $\mathrm{FSH}$ and $\mathrm{LH}$, and ovarian function in heifers. Journal of Reproduction and Fertility 105 263-270.

Gorman SP, Levy JK, Hampton AL, Collante WR, Harris AL \& Brown RG 2002 Evaluation of a porcine zona pellucida vaccine for the immunocontraception of domestic kittens, Felis catus. Theriogenology 58 135-149.

Gurevitch J \& Hedges LV 1999 Statistical issues in ecological metaanalyses. Ecology 80 1142-1149.

Harrenstien LA, Munson L, Chassy LM, Liu IKM \& Kirkpatrick JF 2004 Effects of porcine zona pellucida immunocontraceptives in zoo felids. Journal of Zoo and Wildlife Medicine 35 271-279.

Hayes KT, Feistner ATC \& Halliwell EC 1996 The effect of contraceptive implants on the behavior of female Rodrigues fruit bats, Pteropus rodricensis. Zoo Biology 15 21-36.

Heilmann TJ, Garrott RA, Cadwell LL \& Tiller BL 1998 Behavioral response of free-ranging elk treated with an immunocontraceptive vaccine. Journal of Wildlife Management 62 243-250.

Herbert CA, Trigg TE, Renfree MB, Shaw G, Eckery DC \& Cooper DW 2005 Long-term effects of deslorelin implants on reproduction in the female tammar wallaby Macropus eugenii. Reproduction 129 361-369.

Herbert CA, Trigg TE \& Cooper DW 2006 Fertility control in female eastern grey kangaroos using the $\mathrm{GnRH}$ agonist deslorelin 1 effects on reproduction. Wildlife Research 33 41-46.

Hernandez S, Locke SL, Cook MW, Harveson LA, Davis DS, Lopez RR, Silvy NJ \& Fraker MA 2006 Effects of Spayvac ${ }^{\circledR}$ on urban female whitetailed deer movements. Wildlife Society Bulletin 34 1430-1434.

Huxsoll CC, Price EO \& Adams TE 1998 Testis function, carcass traits, and aggressive behavior of beef bulls actively immunized against gonadotropin-releasing hormone. Journal of Animal Science 76 1760-1766.
Ivanova M, Petrov M, Klissourska D \& Mollova M 1995 Contraceptive potential of porcine zona-pellucida in cats. Theriogenology 43 969-981.

Jacob J \& Matulessy J 2004 Effects of imposed sterility on movement patterns of female ricefield rats. Journal of Wildlife Management 68 $1138-1144$.

Ji WH, Clout MN \& Sarre SD 2000 Responses of male brushtail possums to sterile females: implications for biological control. Journal of Applied Ecology 37 926-934.

Jolly SE, Scobie S \& Cowan PE 1996 Effects of vaccination against gonadotrophin-releasing hormone $\mathrm{GnRH}$ on the social status of brushtail possums in captivity. New Zealand Journal of Zoology 23 325-330.

Kerr PJ, Twigg LE, Silvers L, Lowe TJ \& Forrester RI 1998 Serological monitoring of the epidemiology of myxoma virus to assess the effects of imposed fertility control of female rabbits on myxomatosis. Wildlife Research 25 123-131.

Kirkpatrick JF 2007 Measuring the effects of wildlife contraception: the argument for comparing apples with oranges. Reproduction, Fertility, and Development 19 548-552.

Kirkpatrick JF \& Turner JW 1991 Reversible contraception in nondomestic animals. Journal of Zoo and Wildlife Medicine 22 392-408.

Kirkpatrick JF \& Turner A 2002 Reversibility of action and safety during pregnancy of immunization against porcine zona pellucida in wild mares Equus caballus. Reproduction Supplement 60 197-202.

Kirkpatrick JF \& Turner A 2007 Immunocontraception and increased longevity in equids. Zoo Biology 26 237-244.

Kirkpatrick JF, Liu IM, Turner JW Jr, Naugle R \& Keiper R 1992 Long-term effects of porcine zonae pellucidae immunocontraception on ovarian function in feral horses Equus caballus. Journal of Reproduction and Fertility 94 437-444.

Kirkpatrick JF, Turner JW Jr, Liu IK \& Fayrer-Hosken R 1996 Applications of pig zona pellucida immunocontraception to wildlife fertility control. Journal of Reproduction and Fertility Supplement 50 183-189.

Kitchener AL, Edds LM, Molinia FC \& Kay DJ 2002 Porcine zonae pellucidae immunization of tammar wallabies Macropus eugenii: fertility and immune responses. Reproduction, Fertility, and Development 14 215-223.

Kiyma Z, Adams TE, Hess BW, Riley ML, Murdoch WJ \& Moss GE 2000 Gonadal function, sexual behavior, feedlot performance, and carcass traits of ram lambs actively immunized against GnRH. Journal of Animal Science 78 2237-2243.

Littin KE, Mellor DJ, Warburton B \& Eason CT 2004 Animal welfare and ethical issues relevant to the humane control of vertebrate pests. New Zealand Veterinary Journal 52 1-10.

Loretti AP, Ilah MRS, Ordas J \& de las Mulas JM 2005 Clinical, pathological and immunohistochemical study of feline mammary fibroepithelial hyperplasia following a single injection of depot medroxyprogesterone acetate. Journal of Feline Medicine and Surgery 7 43-52.

Maclellan LJ, Bergfeld EGM, Earl CR, Fitzpatrick LA, Aspden WJ, Kinder JE, Walsh J, Trigg TE \& D'Occhio MJ 1997 Influence of the luteinizing hormone-releasing-hormone agonist, deslorelin, on patterns of estradiol17 beta and luteinizing hormone secretion, ovarian follicular responses to superstimulation with follicle-stimulating hormone, and recovery and in vitro development of oocytes in heifer calves. Biology of Reproduction 56 878-884.

Magiafoglou A, Schiffer M, Hoffmann AA \& McKechnie SW 2003 Immunocontraception for population control: will resistance evolve? Immunology and Cell Biology 81 152-159.

Mahi-Brown CA, Yanagimachi RJ, Hoffman C \& Huang TTF Jr 1985 Fertility control in the bitch by active immunization with porcone zonae pellucidae: use of different adjuvants and patterns of estradiol and progesterone levels in estrous cycles. Biology of Reproduction 32 761-772.

Mahi-Brown CA, Yanagimachi RJ, Nelson ML, Yanagimachi H \& Palumbo N 1988 Ovarian histopathology of bitches immunized with porcine zonae pellucidae. American Journal of Reproductive Immunology 18 94-103.

Mattos R, Orlandi C, Williams J, Staples CR, Trigg T \& Thatcher WW 2001 Effect of an implant containing the GnRH agonist deslorelin on secretion of $\mathrm{LH}$, ovarian activity and milk yield of postpartum dairy cows. Theriogenology 56 371-386. 
McNeilly AS \& Fraser HM 1987 Effect of gonadotropin-releasing-hormone agonist-induced suppression of $\mathrm{LH}$ and $\mathrm{FSH}$ on follicle growth and corpus-luteum function in the ewe. Journal of Endocrinology 115 273-282.

McShea WJ, Monfort SL, Hakim S, Kirkpatrick J, Liu I, Turner JW Jr, Chassy L \& Munson L 1997 The effect of immunocontraception on the behavior and reproduction of white-tailed deer. Journal of Wildlife Management 61 560-569.

Miller LA, Johns BE, Elias DJ \& Crane KA 1997 Comparative efficacy of two immunocontraceptive vaccines. Vaccine 15 1858-1862.

Miller LA, Johns BE \& Killian GJ 2000a Immunocontraception of whitetailed deer with $\mathrm{GnRH}$ vaccine. American Journal of Reproductive Immunology 44 266-274.

Miller LA, Johns BE \& Killian GJ $2000 b$ Long-term effects of PZP immunization on reproduction in white-tailed deer. Vaccine $\mathbf{1 8}$ 568-574.

Miller LA, Johns BE \& Killian GJ 2000c Immunocontraception of whitetailed deer using native and recombinant zona pellucida vaccines. Animal Reproduction Science 63 187-195.

Miller LA, Rhyan JC \& Drew M 2004 Contraception of bison by GnRH vaccine: a possible means of decreasing transmission of brucellosis in bison. Journal of Wildlife Diseases 40 725-730.

Moudgal NR, Murthy GS, Rao AV, Ravindranath N, Sairam M, Kotago SG \& Martin F 1986 Immunization against FSH as a method of male contraceptive. In Immunological Approaches to Contraception and Promotion of Fertility, pp 101-113. Ed. GP Talwar. New York: Plenum Press.

Munson L, Gardner IA, Mason RJ, Chassy LM \& Seal US 2002 Endometrial hyperplasia and mineralization in zoo felids treated with melengestrol acetate contraceptives. Veterinary Pathology 39 419-427.

Nave CD, Shaw G, Short RV \& Renfree MB 2000 Contraceptive effects of levonorgestrel implants in a marsupial. Reproduction, Fertility, and Development 12 81-86.

Nettles VF 1997 Potential consequences and problems with wildlife contraceptives. Reproduction, Fertility, and Development 9 137-143.

Patton ML, White AM, Swaisgood RR, Sproul RL, Fetter GA, Kennedy J, Edwards MS, Rieches RG \& Lance VA 2001 Aggression control in a bachelor herd of fringe-eared oryx Oryx gazella callotis, with melengestrol acetate: behavioral and endocrine observations. Zoo Biology 20 375-388.

Patton ML, Jochle SM \& Penfold LM 2007 Review of contraception in ungulate species. Zoo Biology 26 311-326.

Poiani A, Coulson G, Salamon D, Holland S \& Nave CD 2002 Fertility control of Eastern grey kangaroos: do levonorgestrel implants affect behavior? Journal of Wildlife Management 66 59-66.

Portugal MM \& Asa CS 1995 Effects of chronic melengestrol acetate contraceptive treatment on perineal tumescence, body-weight, and sociosexual behavior of hamadryas baboons Papio-Hamadryas. Zoo Biology 14 251-259.

Powell DM 1999 Preliminary evaluation of porcine zona pellucida PZP immunocontraception for behavioral effects in feral horses Equus caballus. Journal of Applied Animal Welfare Science 2 321-335.

Primakoff P, Lapthrop W, Woolman L, Cowan A \& Myles D 1988 Fully effective contraception in the male and female guinea pigs immunized with the sperm antigen PH-20. Nature 335 543-546.

Ramsey D 2007 Effects of fertility control on behavior and disease transmission in brushtail possums. Journal of Wildlife Management $\mathbf{7 1}$ 109-116.

Rhim SH, Millar SE, Robey F, Luo AM, Lou YH, Yule T, Allen P, Dean J \& Tung KSK 1992 Autoimmune-disease of the ovary induced by a zp3-peptide from the mouse zona-pellucida. Journal of Clinical Investigation 89 28-35.

Rubion S, Desmoulins PO, Riviere-Godet E, Kinziger M, Salavert F, Rutten F, Flochlay-Sigognault A \& Driancourt MA 2006 Treatment with a subcutaneous GnRH agonist containing controlled release device reversibly prevents puberty in bitches. Theriogenology 66 1651-1654.

Sacco AG 1987 Zonae pellucidae: current status as a candidate antigen for contraceptive vaccine development. American Journal of Reproductive Immunology and Microbiology 15 122-130.
Sacco AG, Subramanian MG \& Yurewicz EC 1984 Association of sperm receptor activity with a purified pig zona antigen PPZA. Journal of Reproductive Immunology 6 89-103.

Saunders G, Mcllroy J, Berghout M, Kay B, Gifford E, Perry R \& van de Ven R 2002 The effects of induced sterility on the territorial behavior and survival of foxes. Journal of Applied Ecology 39 56-66.

Schwarzer R 1989 Meta-Analysis Programs (Computer Program and Manual) v 5.3., Berlin, West Germany: Institute fur Psycologie, Freie Universitat Berlin.

Scott EM, Fitzpatrick JL, Nolan AM, Reid J \& Wiseman ML 2003 Evaluation of welfare state based on interpretation of multiple indices. Animal Welfare 12 457-468.

Seal US 1991 Fertility-control as a tool for regulating captive and freeranging wildlife populations. Journal of Zoo and Wildlife Medicine $\mathbf{2 2}$ $1-5$.

Sehgal S, Gupta SK \& Bhatnagar P 1989 Long-term effects of immunization with porcine zona pellucida on rabbit ovaries. Pathology 21 105-110.

Sokolowski JH \& VanRavenswaay F 1976 Effects of melengestrol acetate on reproduction in the beagle bitch. American Journal of Veterinary Research 37 943-945.

Stoops MA, Liu IKM, Shideler SE, Lasley BL, Fayrer-Hosken RA, Benirschke K, Murata K, van Leeuwen EMG \& Anderson GB 2006 Effect of porcine zonae pellucidae immunisation on ovarian follicular development and endocrine function in domestic ewes Ovis aries. Reproduction, Fertility, and Development 18 667-676.

Stout RJ, Knuth BA \& Curtis PD 1997 Preferences of suburban landowners for deer management techniques: a step towards better communication. Wildlife Society Bulletin 25 348-359.

Talwar GP 1985 Immunobiology of gonadotropin-releasing hormone. Journal of Steroid Biochemistry 23 795-800.

Turner A \& Kirkpatrick JF 2002 Effects of immunocontraception on population, longevity and body condition in wild mares Equus caballus. Reproduction Supplement 60 187-195.

Tuyttens FAM \& MacDonald DW 1998 Fertility control: an option for nonlethal control of wild carnivores? Animal Welfare 7 339-364.

Twigg LE, Lowe TJ, Martin GR, Wheeler AG, Gray GS, Griffin SL, O'Reilly CM, Robinson DJ \& Hubach PH 2000 Effects of surgically imposed sterility on free-ranging rabbit populations. Journal of Applied Ecology 37 16-39.

Walter WD, Kilpatrick HJ \& Gregonis MA 2003 Does immunocontraception improve condition of free-ranging female white-tailed deer? Journal of Wildlife Management 67 762-766.

Williams GC 1966 Natural selection, the costs of reproduction, and a refinement of Lack's principle. American Naturalist 100 687-690.

Williams CK, Davey CC, Moore RJ, Hinds LA, Silvers LE, Kerr PJ, French N, Hood GM, Pech RP \& Krebs CJ 2007 Population responses to sterility imposed on female European rabbits. Journal of Applied Ecology $\mathbf{4 4}$ 291-301.

Wood DM, Liu C \& Dunbar BS 1981 Effects of alloimmunization and heteroimmunization with zonae pellucidae on fertility in rabbits. Biology of Reproduction 25 439-450.

Woodward R, Herberstein ME \& Herbert CA 2006 Fertility control in female eastern grey kangaroos using the $\mathrm{GnRH}$ agonist deslorelin 2 effects on behavior. Wildlife Research 33 47-55.

Zeng XY, Turkstra JA, Tsigos A, Meloen RH, Liu XY, Chen FQ, Schaaper WMM, Oonk HB, Guo DZ \& van de Wiel DFM 2002 Effects of active immunization against $\mathrm{GnRH}$ on serum $\mathrm{LH}$, inhibin $\mathrm{A}$, sexual development and growth rate in Chinese female pigs. Theriogenology 58 1315-1326.

Received 3 November 2008

First decision 9 February 2009

Revised manuscript received 24 July 2009

Accepted 5 August 2009 